\title{
Carbendazim dissipation in the biomixture of on-farm biopurification systems and its effect on microbial communities
}

\author{
G.R. Tortella ${ }^{\mathrm{a}, *}$, R.A. Mella-Herrera ${ }^{\text {a }}$, D.Z. Sousa ${ }^{\mathrm{b}}$, O. Rubilar ${ }^{\mathrm{a}}$, G. Briceño ${ }^{\mathrm{a}}$, L. Parra ${ }^{\mathrm{c}}$, M.C. Diez $^{\mathrm{a}}$ \\ a Departamento de Ingeniería Química, Universidad de La Frontera, Casilla 54-D, Temuco, Chile \\ ${ }^{\mathrm{b}}$ IBB-Institute for Biotechnology and Bioengineering, Centre of Biological Engineering, University of Minho, Campus de Gualtar, $4710-057$ Braga, Portugal \\ ${ }^{\mathrm{c}}$ Departamento de Ciencias Químicas y Recursos Naturales, Universidad de La Frontera, Casilla 54-D, Temuco, Chile
}

\section{H I G H L I G H T S}

- Microbiological impact of carbendazim at high doses on biopurification system was evaluated.

- Efficient carbendazim degradation occurred after three successive applications.

- Enzyme activities were affected, but recovered quickly after each carbendazim application.

- Carbendazim did not significantly change the structure of microbial communities.

-We demonstrate the robustness of this biological system from a microbiological viewpoint.

\section{A R T I C L E I N F O}

\section{Article history:}

Received 26 March 2013

Received in revised form 26 May 2013

Accepted 29 May 2013

Available online 24 June 2013

\section{Keywords:}

Microbial community

Pesticides

On-farm biopurification system

Carbendazim dissipation

\begin{abstract}
A B S T R A C T
The impact of repeated carbendazim (CARB) applications on the extent of CARB dissipation, the microbial diversity, the community level physiological profile (CLPP), and the enzymatic activity within the biomixture of an on-farm biopurification system was evaluated. After three successive CARB applications, the CARB dissipation efficiency was high; the efficiency of dissipation was $87 \%, 94 \%$ and $96 \%$ after each application, respectively. Although microbial enzymatic activity was affected significantly by CARB application, it could recover after each CARB pulse. Likewise, the numbers of cultivable bacteria, fungi and actinomycetes (as measured in CFUs) were slightly affected by the addition of CARB, but the inhibitory effect of the pesticide application was temporary. Denaturing gradient gel electrophoresis (DGGE) and Biolog Ecoplate assays demonstrated that the microbial populations remained relatively stable over time when compared to the control. The results obtained herein therefore demonstrate the high dissipation capacity of this biomixture and highlight the microbiological robustness of this biological system.
\end{abstract}

(c) 2013 Elsevier Ltd. All rights reserved.

\section{Introduction}

On-farm biopurification systems, termed "biobeds", are a biotechnological tool widely distributed in Europe and, more recently, in South America as well. Such systems were designed and implemented to mitigate point source contamination by agriculture pesticides (Torstensson and Castillo, 1997). This system is designed with several components, of which the principal component is the biomixture (Castillo et al., 2008). The biomixture is typically composed of straw, peat and topsoil in a volumetric proportion of 2:1:1. The traditional biomixture (Swedish biomixture, see Torstensson and Castillo, 1997) has been modified to alternative biomixtures in other countries for specialised purposes (Coppola et al., 2007; Karanasios et al., 2010). An efficient biomixture must have the capacity to retain and degrade contaminants by promoting

\footnotetext{
* Corresponding author. Tel.: +56 45 325487; fax: +56 45325053.

E-mail address: gtortell@ufro.cl (G.R. Tortella).
}

the development of numerous and robust degrading microorganisms, especially white rot fungi. Such organisms can degrade pesticides with extracellular enzymes, such as phenoloxidases (Castillo et al., 2008). Several systems have been developed in recent years for pesticide degradation using traditional and modified biomixtures (Fogg et al., 2003; Coppola et al., 2007; Vischetti et al., 2008; Karanasios et al., 2010; Tortella et al., 2012), including full-scale model biobeds (Spliid et al., 2006; Omirou et al., 2012). However, the effects of the pesticides and their interactions with the microbial communities of the biomixture systems are not yet fully understood (Castillo et al., 2008; Karanasios et al., 2012). In soil, pesticides are known to have a significant effect on local microorganisms, causing changes in nutrient turnover rates, the microbial community structure and soil quality (Chowdhury et al., 2008; Kalia and Gosal, 2011; Muñoz-Leoz et al., 2011, 2013; Cycón et al., 2012; Imfeld and Vuilleumier, 2012). It is therefore reasonable to expect that pesticides might also affect the microbial populations in the biopurification system biomixtures. A better understanding of the microbiology of 
such biomixtures will be crucial to understand the impact of pesticides on the microbial functional diversity and microbial communities within the biomixture. This information is needed to ensure the long-term sustainability of the biological systems for agricultural purposes. The current literature suggests that microbial communities in a pesticide-contaminated biomixture are adversely affected, though recovery is normally observed over time. Vischetti et al. (2008) reported a negative effect of chlorpyrifos and metalaxyl on the microbial communities of an alternative biomixture (composed of vine/branches, urban wastes/garden compost and soil), but as soon as the pesticide concentration decreased, the microbial activity was found to recover. Similar results were reported by Coppola et al. (2011) and by Marinozzi et al. (in press) regarding the effects of different fungicides on the microbial diversity of modified biomixture systems (composed of either compost and straw or pruning residues and straw, respectively). Interestingly, the effect of pesticides on the traditional biomixture of straw, peat and soil, which is the most widely used biomixture for on-farm biopurification systems, has not been extensively studied and is therefore the subject of this research. Here, carbendazim (CARB, methyl 2-benzimidazole carbamate) was used as a model contaminant. CARB is a broadspectrum benzimidazole fungicide that is widely used to control foliar diseases on arable crops such as cereals, sugar and fodder beet, oil seed rape and fruits (EFSA, 2010). CARB is also a major degradation product of other common fungicides, including benomyl and thiphanate-methyl (Mazellier et al., 2002). CARB poses a high environmental concern due to its persistence in soil and its known adverse effect on soil microorganisms (Grogan and Jukes, 2003; Yan et al., 2011). The estimated single first order $\mathrm{DT}_{50}$ of CARB (time needed for disappearance of half the chemical) is $26-40 \mathrm{~d}$ (at $20^{\circ} \mathrm{C}$ and $10 \mathrm{kPa}$ soil moisture) (EFSA 2010). However, comprehensive information regarding the route of aerobic degradation of CARB in soil is lacking and detailed identification and quantification of degradation metabolites not available (EFSA 2010).

The aims of the present study were to evaluate the dissipation of CARB within the traditional biomixture and to evaluate the impact of repeated high-concentration CARB applications on the microbial composition, functional microbial diversity and enzymatic activities of the biomixture system.

\section{Materials and methods}

\subsection{Chemicals}

Analytical standard carbendazim (CARB) (99\% purity) was purchased from Sigma Aldrich, Chile. Commercial formulation CARB (Itabarb 50\%) was supplied by Solchem Ltda., Chile. MBTH (3methyl-2-benzothiazolinone hydrazone) and DMAB (3-(dimethylamino) benzoic acid) were purchased from Sigma Aldrich, Chile. All other chemicals and solvents were of analytical reagent grade and were purchased from Equilab Ltda. and Merck S.A (Chile).

\subsection{Biomixture preparation}

The biomixture was prepared by mixing top soil, commercial peat (36.6\% organic carbon) and winter wheat straw (34.0\% organic carbon) in the volumetric proportion of $1: 1: 2$. Topsoil $(0-20 \mathrm{~cm})$ was collected from the experimental station Maquehue (Andisol Freire series; $38^{\circ} 50^{\prime} \mathrm{S}, 72^{\circ} 41^{\prime} \mathrm{W}$ ) at La Frontera University; this site had no history of CARB contamination. The soil was mainly composed of sand (30.7\%), silt (41.8\%), clay (27.4\%), and organic matter (18\%) and had a pH of 6.1. Wheat straw was cut in fragments of approximately $3 \mathrm{~mm}$ using a food processor, and the soil and peat were sieved through a $3 \mathrm{~mm}$ mesh. The constituents were then mixed vigorously and homogenised by hand mixing. The resulting biomixture was placed in a polypropylene bag and the moisture content corrected to approximately $60 \%$ of its water holding capacity (WHC) using sterile distilled water. The biomixture was left to mature for $150 \mathrm{~d}$ at $25 \pm 2{ }^{\circ} \mathrm{C}$; moisture content was kept stable by regular additions of sterile distilled water.

\subsection{Experimental design and CARB treatments}

Bulk samples $(2.0 \mathrm{~kg})$ of mature biomixture were placed in six glass containers $(40 \times 20 \times 10 \mathrm{~cm}$ deep $)$. Three of these containers were artificially contaminated with CARB (commercial formulation) taken from a stock solution $\left(600 \mathrm{mg} \mathrm{L}^{-1}\right)$. CARB was sprayed to a final concentration of $40 \mathrm{mg}$ a.i $\mathrm{kg}^{-1}$, together with the appropriate amount of distilled water necessary to guarantee a WHC of $60 \%$. The applied CARB dose was approximately forty-fold higher than the recommended field dose (approximately $1 \mathrm{mg} \mathrm{kg}^{-1}$ of soil), in order to mimic a pesticide spill on the biomixture. Two additional CARB doses ( $40 \mathrm{mg}$ a.i $\mathrm{kg}^{-1}$ ) were subsequently applied to the contaminated biomixtures, at 30 and $60 \mathrm{~d}$. CARB was added in high dose because the biomixture of the biobeds was designed to degrade pesticide residues from accidental pesticide spills. Moreover, CARB was added to the biomixture as commercial formulations because co-adjuvants or surfactants present in commercial CARB may affect both degradation rates and their impact on soil microbial communities (Beigel et al., 1999). Biomixture control assays (triplicates) received the same amount of sterile distilled water as CARB-contaminated biomixtures, but no pesticide was sprayed in these assays. Each container was covered with a perforated plastic film to avoid excessive evaporation and incubated in the dark at $25 \pm 2{ }^{\circ} \mathrm{C}$ for a period of $90 \mathrm{~d}$. The biomixture moisture was kept stable by regularly adding sterile distilled water. At fixed intervals, biomixture samples were collected to determine the level of residual CARB and other biological parameters. Residual CARB was extracted from $5 \mathrm{~g}$ of the biomixture with $30 \mathrm{~mL}$ of acetonitrile of HPLC grade ( $2 \mathrm{~h}$ shaking at $350 \mathrm{rpm}$ and $30 \mathrm{~min}$ of ultrasonication). The samples were then centrifuged (13500g), and the resulting supernatant was filtered using a PTFE membrane ( $0.2 \mu \mathrm{m}$ pore size; Millipore) and analysed by liquid chromatography (HPLC). The extraction technique was validated through the contamination of the biomixture samples with CARB at dry weights of 1,10 and $40 \mathrm{mg} \mathrm{kg}^{-1}$. The average recovery numbers after CARB addition were $91 \pm 1.7,93.4 \pm 2.6$ and $95.1 \pm 0.89 \%$, respectively. The CARB degradation in the biomixture followed first-order kinetics, and the CARB concentration at a given postapplication time $(t)$ could be described by the equation $C=C_{0} \cdot e^{-k t}$. The CARB half-life was determined using the equation $t_{1 / 2}=\operatorname{Ln}(2) / k$.

\subsection{Microbial analysis}

\subsubsection{Determination of enzyme activities}

Dehydrogenase activity (DHA) of the biomixture was determined by 2,3,5-Triphenyl Tetrozolium Chloride (TTC) reduction technique (Casida 1977). The biomixture DHA is therefore expressed as $\mu \mathrm{g}$ TPF produced $\mathrm{g}^{-1} \mathrm{~h}^{-1}$.

Acid (AP) and alkaline phosphatase (AKP) activities were determined according to the method of Tabatabai and Bremner (1969), using $p$-nitrophenyl phosphate $(0.05 \mathrm{M})$ as substrate. The phosphatase activity is expressed as $\mu \mathrm{g}$ p-nitrophenol $\mathrm{g}^{-1} \mathrm{~h}^{-1}$ produced.

Hydrolitic activity was measured by monitoring fluorescein diacetate hydrolysis (FDA) according to Schnurer and Rosswall (1982) with slight modifications. The concentration of the released fluorescein was calculated by a calibration curve with standard quantities of FDA and the results were expressed as $\mu \mathrm{g}$ FDA $\mathrm{g}^{-1} \mathrm{~h}^{-1}$. 
Phenoloxidase activity (PA) was determined using an MBTH/ DMAB method previously described by Castillo et al. (1994). No correction was made for the possible presence of lignin peroxidase (LiP) and laccase (Lac) activity, and therefore this measurement may represent the sum of manganese peroxidase, LiP and laccase activities (Castillo and Torstensson, 2007). PA activity is expressed as $\left(\mathrm{U} \mathrm{kg}^{-1}\right)$.

\subsubsection{Enumeration of culturable bacteria}

The total numbers of culturable bacteria, fungi and actinomycetes were counted in the treated and control biomixtures. Biomixture samples $(10 \mathrm{~g}$ d.w.) were placed in Erlenmeyer flasks containing $90 \mathrm{~mL}$ of saline buffer $(0.85 \% \mathrm{NaCl})$ and were shaken at $250 \mathrm{rpm}$ and at $25^{\circ} \mathrm{C}$ for $1 \mathrm{~h}$ to ensure the homogeneous dispersion of the soil particles. After $30 \mathrm{~min}$, the clear supernatant was used for serial dilutions (from $10^{-4}$ to $10^{-7}$ ) and spread onto plate count agar (PCA) medium (Difco Laboratories) containing cycloheximide (100 $\left.\mathrm{mg} \mathrm{L}^{-1}\right)$ to determine the total culturable bacteria, Rose Bengal-Streptomycin Agar (Oxoid Ltd., UK) to determine the total culturable fungi and Bacto-Actinomycete Isolation agar (Difco) to determine the total culturable Actinomycetes. The plates were incubated at $30^{\circ} \mathrm{C}$ for $48 \mathrm{~h}$ for bacteria, $30^{\circ} \mathrm{C}$ for $72 \mathrm{~h}$ for Actinomycetes and $25^{\circ} \mathrm{C}$ for $72 \mathrm{~h}$ for fungi. All results were expressed in colony forming units (CFUs) per $g$ of biomixture.

\subsubsection{Analysis of the community level physiological profiles (CLPPS)}

The CLPPs were assessed by the BiologEcoplate ${ }^{\mathrm{TM}}$ system (Bio$\log$ Inc., CA, USA). Microplates containing 96 wells with 31 sole carbon sources and a water blank, all in triplicate, were inoculated according to the methodology proposed by Fang et al. (2009) with some modifications. A $10^{-1}$ dilution was prepared by suspending $10 \mathrm{~g} \mathrm{~d} . \mathrm{w}$. of the biomixture in $90 \mathrm{~mL}$ of a sterile saline solution $(\mathrm{NaCl}, 0.85 \%)$, which was then mixed on an orbital shaker (250 rpm, $1 \mathrm{~h})$. The solution was maintained at static conditions for $20 \mathrm{~min}$ to allow the partial clarification of the supernatant. The supernatant was then transferred to conical tubes and centrifuged $(6000 \mathrm{~g}, 10 \mathrm{~min})$. The pellet obtained was resuspended in a sterile physiological saline solution. Serial dilutions were made (from $10^{-2}$ to $10^{-4}$ ), and the viable cell number was obtained from the dilution of $10^{-3}$ or $10^{-4}$ using the LIVE/DEAD ${ }^{\circledR}$ BacLight ${ }^{\mathrm{TM}}$ Bacterial Viability Kit (Invitrogen, Carlsbad, CA). Then, $10^{4}$ viable cells were inoculated into each well and incubated at $25 \pm 1^{\circ} \mathrm{C}$. The colour development in each well was monitored by measuring the absorbance at $590 \mathrm{~nm}$ at regular intervals over a period of $74 \mathrm{~h}$ using a Bio-Tek ELx800 microplate reader (Bio-Tek Instrument Inc., USA).

The microbial activity of each microplate was expressed as the average well-colour development (AWCD) and was determined as previously described by Garland and Mills (1991) as follows: $\mathrm{AWCD}=\sum \mathrm{OD}_{i} / 31$, where $\mathrm{OD}_{i}$ indicates the optical density of substrate $i$ divided by the lowest optical density, measured in the water blank well at $590 \mathrm{~nm}$. Furthermore, the biomixture diversity index was calculated as described previously by Fang et al. (2009), as follows:

\section{Shannon-Weaver index $H=\sum p_{i}\left(\ln p_{i}\right)$}

\section{Shannon-Evenness index $E=H^{\prime} / \ln S$}

Here, $p_{i}$ is the proportional colour development of the $i$ th well over the total colour development of all the wells. $S$ is the number of wells with colour development (substrate utilisation richness).

\subsubsection{Analysis of the soil microbial community structure by PCR-} DGGE

The total DNA of the microbial community was extracted from the biomixture $(0.4 \mathrm{~g})$ at $0,10,30,40,60,70$ and $90 \mathrm{~d}$, using the NucleoSpin Soil DNA Isolation Kit (Macherey-Nagel GmbH \& Co. Germany), according to the manufacturer's instructions. After extraction, the DNA was stored at $-20^{\circ} \mathrm{C}$ until further analysis. The DNA integrity was assessed via electrophoresis on a $0.8 \%$ agarose gel containing the SYBR ${ }^{\circledR}$ Safe DNA gel stain, and the amount of DNA was quantified with the Epoch Micro-Volume Spectrophotometer System (Bio-Tek Instrument Inc, USA).

PCR amplifications were performed using GoTaq ${ }^{\circledR}$ DNA Polymerase (Promega, Co. Madison, WI, USA), and the reaction products were visualised under UV light in agarose gel $(0.8 \%)$ stained with SYBR ${ }^{\circledR}$ Safe.

The bacterial DNA was amplified with primers F341-GC and R534, which target the V3 variable region of the 16S rRNA gene (Muyzer et al., 1993). Positive (Pseudomonas spp.) and negative controls were run for every set of PCR reactions. The PCR reaction mixtures consisted of $20 \mathrm{mM}$ Tris- $\mathrm{HCl}$ (pH 8.4), $50 \mathrm{mM} \mathrm{KCl,} 3 \mathrm{mM}$ $\mathrm{MgCl}_{2}, 200 \mu \mathrm{M}$ of each of the four deoxynucleoside triphosphates (dNTP), $2.5 \mathrm{U}$ of Taq polymerase, $200 \mathrm{nM}$ of each primer, and $1 \mu \mathrm{L}$ of appropriately diluted template DNA in a final volume of $50 \mu \mathrm{L}$. The thermocycling program used for amplification was as follows: pre-denaturation at $94^{\circ} \mathrm{C}$ for $4 \mathrm{~min}$; 35 cycles of denaturation at $94{ }^{\circ} \mathrm{C}$ for $45 \mathrm{~s}$, annealing at $63^{\circ} \mathrm{C}$ for $60 \mathrm{~s}$, and elongation at $72{ }^{\circ} \mathrm{C}$ for $30 \mathrm{~s}$; and post-elongation at $72{ }^{\circ} \mathrm{C}$ for $10 \mathrm{~min}$. The reactions were subsequently cooled to $4^{\circ} \mathrm{C}$.

ITS regions of the fungal rRNA gene were amplified using primers ITS3-GC and ITS4 (White et al., 1990). Positive (Anthracophyllum discolor) and negative controls were run for every set of PCR reactions. The thermocycling program used for the fungal rRNA gene amplifications was the following: $94{ }^{\circ} \mathrm{C}$ for $5 \mathrm{~min}$; 35 cycles of $95{ }^{\circ} \mathrm{C}$ for $30 \mathrm{~s}, 55{ }^{\circ} \mathrm{C}$ for $30 \mathrm{~s}$ and $72{ }^{\circ} \mathrm{C}$ for $60 \mathrm{~s}$; and $72{ }^{\circ} \mathrm{C}$ for 5 min.

Actinomycetes rRNA fragments were amplified using nestedPCR. To amplify the 16S rRNA gene from the actinomycetes, primer F243 was used with reverse primer R1378 (Heuer et al., 1997). A total of $1 \mu \mathrm{L}$ of the resulting PCR products was then used as a template for a second PCR reaction with primers F341-GC and R534 (Muyzer et al., 1993). Positive (Streptomyces spp.) and negative controls were used. The following thermocycling program was used for amplification with primer pair F243/R1378: $95^{\circ} \mathrm{C}$ for $5 \mathrm{~min}$; 35 cycles of $95^{\circ} \mathrm{C}$ for $60 \mathrm{~s}, 60^{\circ} \mathrm{C}$ for $60 \mathrm{~s}$ and $72^{\circ} \mathrm{C}$ for $2 \mathrm{~min}$; and $72{ }^{\circ} \mathrm{C}$ for $10 \mathrm{~min}$. The second round of amplification was conducted with the following parameters: $5 \mathrm{~min}$ at $95^{\circ} \mathrm{C} ; 35$ cycles of $95^{\circ} \mathrm{C}$ for $30 \mathrm{~s}, 53^{\circ} \mathrm{C}$ for $30 \mathrm{~s}$ and $72{ }^{\circ} \mathrm{C}$ for $1 \mathrm{~min}$; and 5 min at $72^{\circ} \mathrm{C}$.

The resulting PCR products from the bacteria, fungi and Actinomycetes were then subjected to DGGE analysis using an omniPAGE-DGGE (Cleaver Scientific, Warwickshire, UK). Linear denaturing gradients of $8 \%(\mathrm{w} / \mathrm{v})$ polyacrylamide gel between $40 \%$ and $65 \%$ (for bacteria), $30 \%$ and $70 \%$ (for fungi) and $30-60 \%$ (for Actinomycetes) (urea and formamide) were prepared using the GM-100 Linear Gradient Maker (CBS Scientific, UK). Then, $20 \mu \mathrm{L}$ of PCR products was subjected to gel electrophoresis for $17 \mathrm{~h}$ at $60 \mathrm{~V}$ and $60^{\circ} \mathrm{C}$. After electrophoresis, the gels were stained with silver nitrate as described elsewhere (Sanguinetti et al., 1994).

\subsection{Cluster analysis}

The cluster analysis of the DGGE profiles was performed using the Phoretix 1D software (Nonlinear Dynamics, Durham, USA). Similarity indices of the different profiles were calculated using the Pearson correlation coefficient (Hane et al., 1993). The 
clustering of the DGGE patterns was performed using the Unweighted Pair Group Method with Arithmetic Mean (UPGMA).

\subsection{Chemical analysis}

The CARB levels were measured by HPLC using a Merck Hitachi L2130 pump, a Rheodyne 7725 injector with a $20 \mu \mathrm{L}$ loop and a Merck Hitachi L-2455 diode array detector. Separation was achieved with a C18 column (Chromolit RP-18e, $5 \mu \mathrm{m} 4.6 \times 100 \mathrm{~mm}$ ). Eluent A was $1 \mathrm{mM}$ ammonium acetate, and eluent $\mathrm{B}$ was acetonitrile. The flow rate was set at $1.0 \mathrm{~mL} \mathrm{~min}{ }^{-1}$, which is $0-10 \mathrm{~min}$ in isocratic mode. The column temperature was maintained at $30^{\circ} \mathrm{C}$. The detector was set at $290 \mathrm{~nm}$ for the data acquisition. The instrument calibrations and experimental quantifications were performed against pure reference standards $\left(0.1-10 \mathrm{mg} \mathrm{L}^{-1}\right)$ of CARB.

\subsection{Statistical analysis}

Experiments were conducted using completely randomized block design with three independent replicates. Data were subjected to a one-way analysis of variance (ANOVA) and the averages were compared by Duncan's multiple range tests with a level of 0.95 .

\section{Results and discussion}

\subsection{Carbendazim dissipation in the biomixture after repeated applications}

Fig. 1 shows the pattern of CARB dissipation from the biomixture. Approximately $87 \%, 94 \%$ and $96 \%$ of the CARB dissipated within $30 \mathrm{~d}$ after the first, second and third pesticide applications, respectively. An accelerated level of CARB dissipation can be observed after repeated pesticide applications. This finding might be due to the adaptation of the degrading microorganisms in the biomixture following repeated pesticide applications. These results are in agreement with those of Yu et al. (2009), who reported that the dissipation of CARB in soil could be accelerated by repeated pesticide applications. Similar results were obtained by Vischetti et al. (2008), based on their work with a modified biomixture of biobed that was composed of vine/branches and urban waste/garden compost. They found that the fungicide metalaxyl was rapidly degraded after three successive applications and that the half-life $\left(t_{1 / 2}\right)$ was reduced from $37 \mathrm{~d}$ after the first metalaxyl application to just $4 \mathrm{~d}$ after the third application. The kinetic data derived from the first-order function (Table 1) showed that dissipation of CARB in the traditional biomixture evaluated here also increased

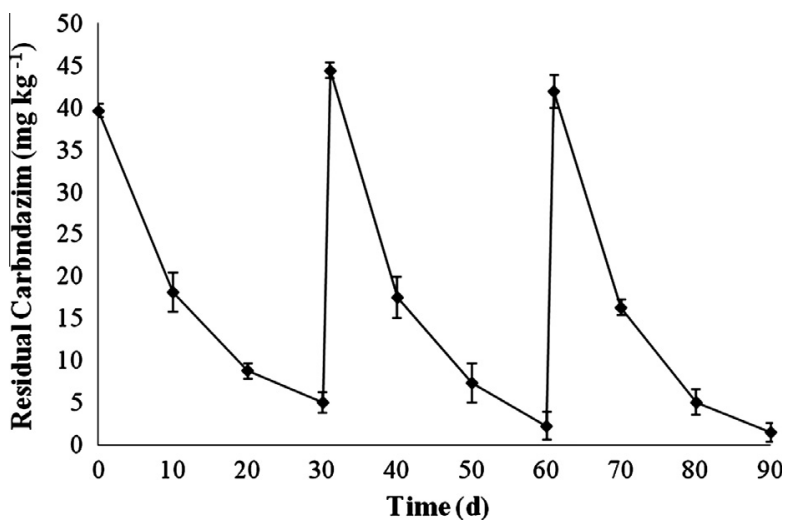

Fig. 1. Residual carbendazim (CARB) in the biomixture after repeated applications at $40 \mathrm{mg} \mathrm{kg}^{-1}$ and incubated at $25 \pm 2{ }^{\circ} \mathrm{C}$ during $90 \mathrm{~d}$.
Table 1

Kinetic data for carbendazim degradation in the biomixture treated with 3 successive applications at $40 \mathrm{mg} \mathrm{kg}^{-1}$ and incubated at $25 \pm 2{ }^{\circ} \mathrm{C}$ during $90 \mathrm{~d}$. Different letters show significant differences between application frequency. Mean values $(n=3)$ with Duncan test $(p \leqslant 0.05)$

\begin{tabular}{lllll}
\hline Application frequency & $C_{0}\left(\mathrm{mg} \mathrm{kg}^{-1}\right)$ & $K\left(\mathrm{~d}^{-1}\right)$ & $t_{1 / 2}$ & $R^{2}$ \\
\hline 1 & $39.6 \pm 0.78$ & $0.06 \pm 0.001 \mathrm{a}$ & $10.0 \pm 0.05 \mathrm{a}$ & 0.98 \\
2 & $44.4 \pm 0.91$ & $0.10 \pm 0.004 \mathrm{~b}$ & $7.1 \pm 0.65 \mathrm{~b}$ & 0.98 \\
3 & $41.9 \pm 1.12$ & $0.11 \pm 0.003 \mathrm{~b}$ & $6.2 \pm 0.07 \mathrm{c}$ & 0.97 \\
\hline
\end{tabular}

remarkably, with a dissipation rate constant that changed from 0.07 to $0.11 \mathrm{~d}^{-1}$ and a $t_{1 / 2}$ that changed from 10 to $6.2 \mathrm{~d}$ after the first and third applications, respectively.

\subsection{Biological activities}

The enzymatic activities measured in the biomixture during the three successive applications of CARB are shown in Fig. 2. Acid (AP) and alkaline phosphatase (AKP) activities fluctuated during the $90 \mathrm{~d}$ of incubation (Fig. $2 \mathrm{a}$ and b). AP activity ranged from 2 to $9 \mu \mathrm{g} \mathrm{PNF} \mathrm{g}^{-1} \mathrm{~h}^{-1}$, for both the CARB-contaminated and the control biomixtures (Fig. 2a). A strong negative effect on AP was observed immediately after CARB addition, and significant differences $(p<0.05)$ in the AP values compared to the control were noted. Nevertheless, the AP levels recovered shortly after each CARB pulse, which suggests that an adaptive response is occurring within the microbial communities of the biomixture. AKP activity ranged from 0.3 to $4.6 \mu \mathrm{g}$ PNF $\mathrm{g}^{-1} \mathrm{~h}^{-1}$ in both the CARB-treated biomixture and the control (Fig. 2b). AKP was not strongly affected by the first and second CARB pulse. However, a significant reduction in AKP activity compared with the control $(p<0.05)$ was evident after the third CARB pulse (Fig. 2b). Nevertheless, the AKP activity quickly recovered after the last CARB application. The reasons for that AKP was affected only after the third application of CARB are unclear. In this sense, we hypothesized that an adaptation of specific microbial populations and improved CARB degradation in the biomixture, may not necessarily be related to adaptation of microbial communities related with phosphorous cycle, given that has been reported that phosphatase activity can be stimulated or inhibited by pesticides (Muñoz-Leoz et al., 2011; Punitha et al., 2012). Phosphatase activity has not been previously described in studies assessing biomixtures within the biobed system. However, Yan et al. (2011) reported an initial inhibitory effect on the neutral phosphatase activity of the soil after the application of CARB at 4 and $8 \mathrm{mg} \mathrm{kg}^{-1}$. The inhibitory effects of high-dose CARB and chlorpyrifos ( 7.5 and $10 \mathrm{~kg} \mathrm{ha}^{-1}$, respectively) on the phosphatase activity of the soil were also reported by Srinivasulu et al. (2012). Our result shows that AP and AKP are temporally affected by the administration of CARB at high doses $\left(40 \mathrm{mg} \mathrm{kg}^{-1}\right.$, which is approximately equivalent to $60 \mathrm{~kg} \mathrm{ha}^{-1}$ ). However, this enzymatic activity could be recovered after pesticide addition, demonstrating the robustness of this biological system.

The dehydrogenase (DH) levels did not show marked fluctuation patterns, with values ranging from 6 to $11 \mu \mathrm{g} \mathrm{g}^{-1} \mathrm{~h}^{-1}$ and 7.5 to $9 \mu \mathrm{g} \mathrm{g}^{-1} \mathrm{~h}^{-1}$ in the contaminated biomixture and the control, respectively (Fig. $2 c)$. A significant $(p<0.05)$ decrease $(25 \%)$ in $\mathrm{DH}$ levels at $30 \mathrm{~d}$, immediately after the second CARB pulse, was observed. However, the DH levels were recovered and higher DH values $\left(10.5 \mu \mathrm{g} \mathrm{g}^{-1} \mathrm{~h}^{-1}\right)$ than in the control $\left(7 \mu \mathrm{g} \mathrm{g}^{-1} \mathrm{~h}^{-1}\right)$ were observed, even following the third CARB application at $60 \mathrm{~d}$ (Fig. 2c). High values obtained in DH activity after second CARB pulse could be related with a possible adaptation of the microorganisms to the presence of the pesticide or probably as a defense mechanism against chemical stress caused by CARB. In this sense, has been reported that CARB in combination with insecticides 

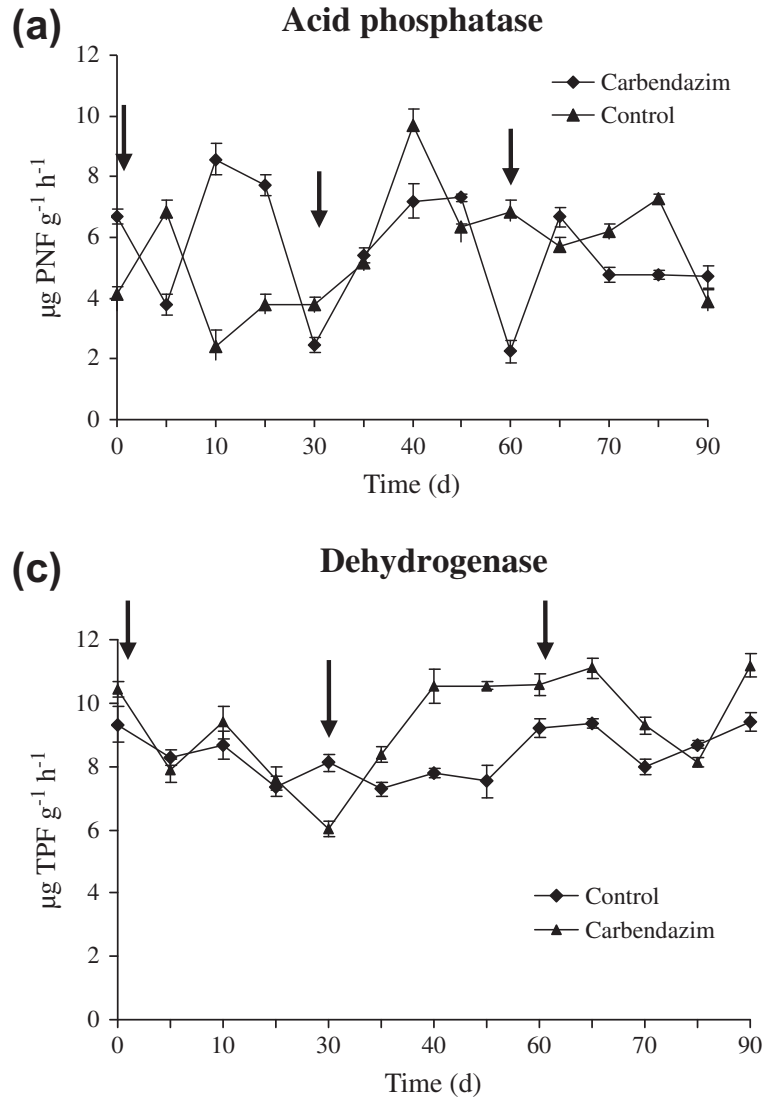
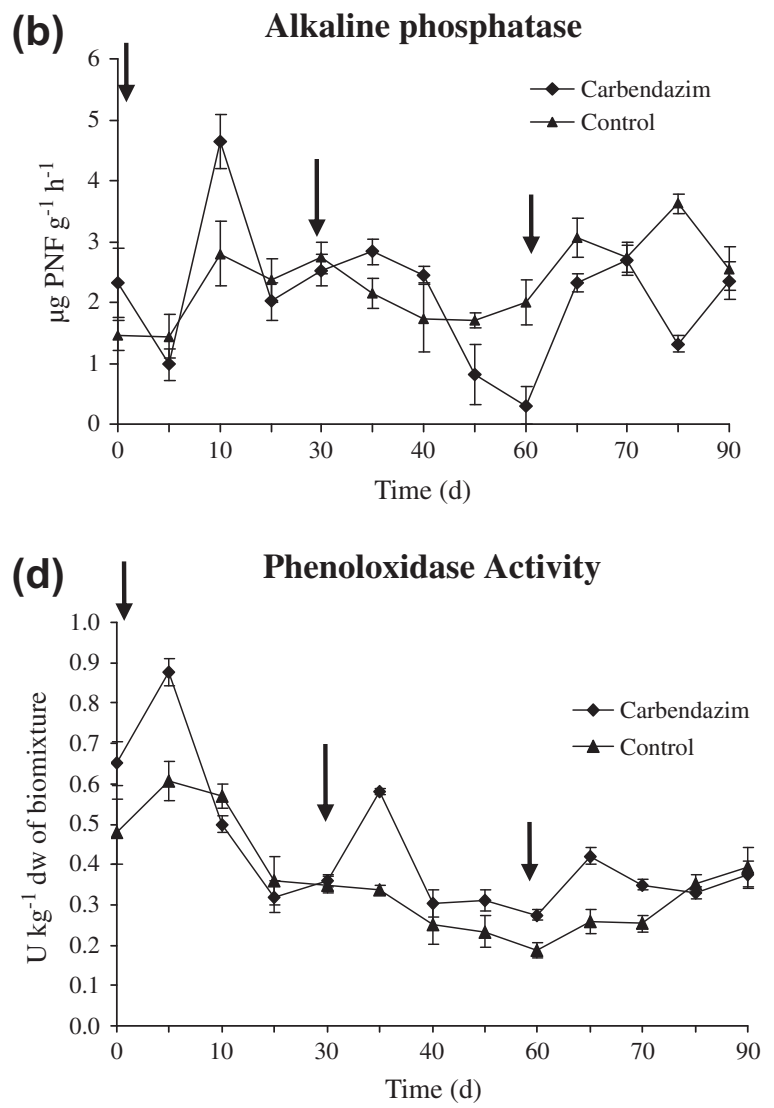

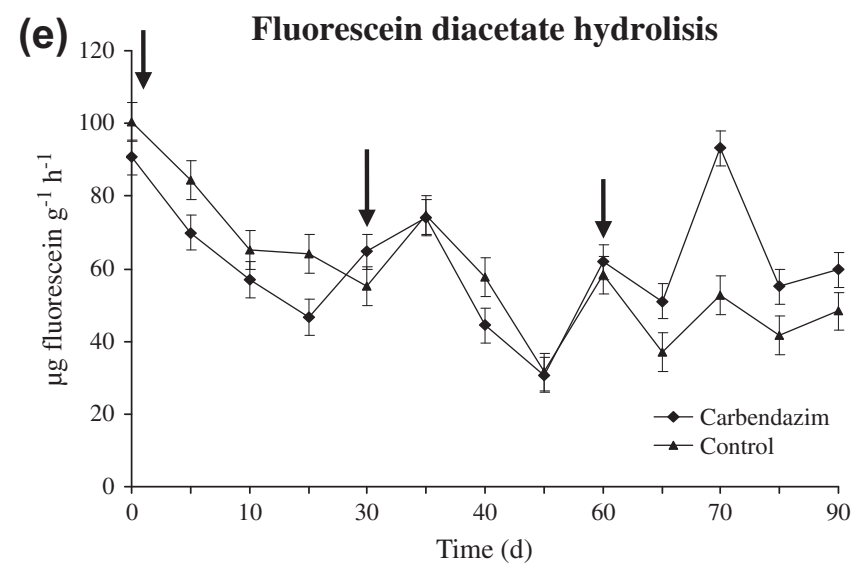

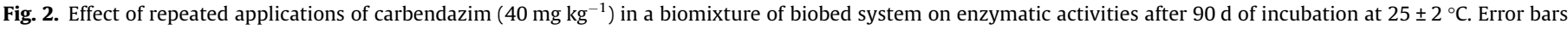
represent the standard error of mean of three replicates $(n=3)$. Arrows indicate day of pesticide application.

caused an increased in DH activity $20 \mathrm{~d}$ after pesticide application (Srinivasulu and Rangaswamy, 2013). As mentioned above, DH activity was negatively affected after each CARB application during initial stages of incubation. However, the biomixture showed a high capacity to recovery this activity quickly. In this sense, fungicide application in soil has showed no a clear tendency when higher concentration of pesticides were added (Muñoz-Leoz et al., 2011, 2013). These authors reported that both stimulation and inhibition of DH was observed after fungicide application.

Phenoloxidase activity was also monitored in the CARB-loaded biomixture and in the control biomixture (Fig. 2d). A notable decrease in phenoloxidase activity could be observed in both the contaminated and the control biomixtures during the 90-d incubation period. However, similar values for phenoloxidase activity were obtained at the end of the experiment $\left(0.4 \mathrm{U} \mathrm{kg}^{-1}\right)$ in both the contaminated and the control biomixtures. A low correlation $(r=0.44)$ between phenoloxidase and CARB dissipation was found, in contrast to the results of Castillo and Torstensson (2007). These authors found that metamitron and chloridazon dissipation were positively correlated with the phenoloxidase content of traditional biomixtures. However, in this experiment, the phenoloxidase activity was effectively stimulated by each CARB pulse in the biomixture, as shown in Fig. 2d.

Fluorescein diacetate hydrolysis (FDA) showed a similar pattern for both the contaminated and the control biomixtures (Fig. 2e). However, after the third CARB pulse, significant differences $(p<0.05)$ and higher FDA values $\left(90 \mu \mathrm{g}\right.$ fluorescein $\left.\mathrm{g}^{-1} \mathrm{~h}^{-1}\right)$ were found in the contaminated biomixture compared to the control 
biomixture ( $50 \mu \mathrm{g}$ fluorescein $\mathrm{g}^{-1} \mathrm{~h}^{-1}$ ). The increase in FDA activity after each successive CARB application suggests that the microbial communities might adapt to the presence of the pesticide, allowing for the enhanced CARB dissipation of the biomixture. Karanasios et al. (2010) studied the FDA levels in pesticides exposed to alternative biomixtures (composed of orange peels, grape stalks, and corn cobs, among other substrates). These authors observed a significant increase in the FDA levels during the first $28 \mathrm{~d}$ of incubation, followed by a gradual decline until $42 \mathrm{~d}$. In the same study, the authors observed a low phenoloxidase activity (manganese peroxidase) in a traditional biomixture (composed of peat, soil and straw) that had been exposed to several pesticides, suggesting that the role of phenoloxidase activity on pesticide degradation was minimal.

Overall, the biological activity levels in the biomixture after three successive pulses of CARB $\left(40 \mathrm{mg} \mathrm{kg}^{-1}\right)$ suggest that the microbial response to CARB exposure occurs relatively fast. This observation could be due to a diminished effect of CARB and/or to the adaptation of the microbial communities to CARB.

\subsection{Community level physiological profiles (CLPPs)}

The CLPPs measured by BiologEcoplate ${ }^{\mathrm{TM}}$ in the biomixture during the three successive applications of CARB are shown in Fig. 3. CARB had an inhibitory effect on microbial functional diversity in the biomixture microbial community, which was revealed by a slight increase in the average well colour development (AWCD) of the CARB-treated samples in the early stage of treatment (Fig. 3 and $0 \mathrm{~d}$ ). However, after the first application of CARB, the microbial functional diversity in the biomixture recovered to the control level (Fig. 3 and $10 \mathrm{~d}$ ). No significant inhibitory effect on the microbial functional diversity was observed following the second application
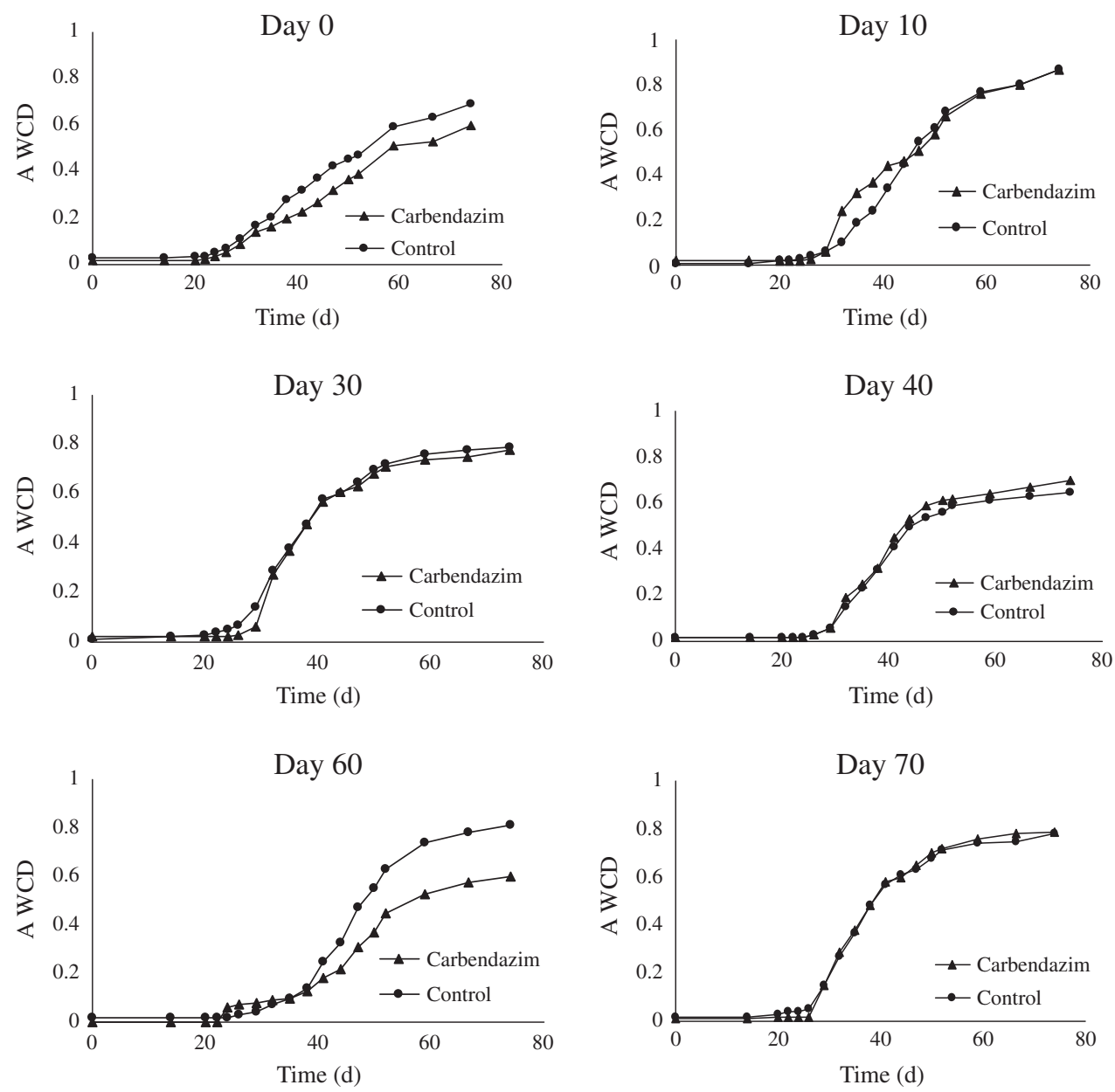

Day 90

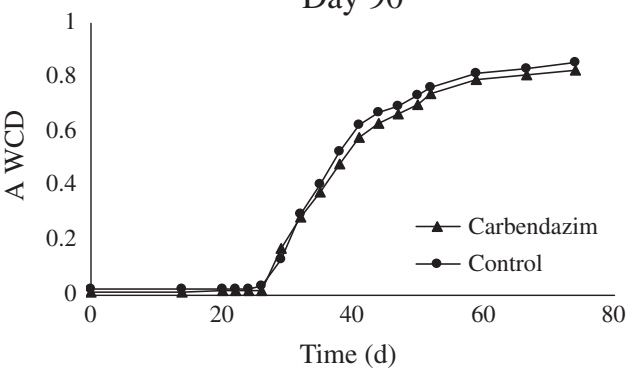

Fig. 3. Average well colour development (AWCD) of biomixture samples at different sampling times. 
Table 2

Diversity indices (Shannon-Weaver index, $H$ and Shannon-Evenness index, $E$ ) of biomixture microbial communities subjected to repeated applications of carbendazim (40 $\mathrm{mg} \mathrm{kg}^{-1}$ ). Different capital or lower case letter show significant differences between CARB and control in the same sampling point or between different sampling point within the same treatment respectively. Mean values $(n=3)$ with Duncan test $(p \leqslant 0.05)$.

\begin{tabular}{llllll}
\hline \multirow{2}{*}{ Time $(\mathrm{d})$} & \multicolumn{2}{l}{ Shannon's $(H)$} & & \multicolumn{2}{l}{ Evenness $(E)$} \\
\cline { 2 - 3 } \cline { 5 - 6 } & Carbendazim & Control & & Carbendazim & Control \\
\hline 0 & $3.08 \pm 0.03 \mathrm{Aa}$ & $3.14 \pm 0.03 \mathrm{Aa}$ & & $0.95 \pm 0.01 \mathrm{Aab}$ & $0.94 \pm 0.01 \mathrm{Aab}$ \\
10 & $2.86 \pm 0.05 \mathrm{Aa}$ & $2.30 \pm 0.05 \mathrm{Bd}$ & & $0.95 \pm 0.01 \mathrm{Aab}$ & $0.93 \pm 0.01 \mathrm{Abc}$ \\
30 & $3.09 \pm 0.04 \mathrm{Aa}$ & $3.09 \pm 0.02 \mathrm{Ba}$ & & $0.95 \pm 0.01 \mathrm{Aab}$ & $0.95 \pm 0.01 \mathrm{Aab}$ \\
40 & $2.96 \pm 0.03 \mathrm{Aa}$ & $2.81 \pm 0.04 \mathrm{Ab}$ & & $0.92 \pm 0.02 \mathrm{Ab}$ & $0.91 \pm 0.03 \mathrm{Ac}$ \\
60 & $2.95 \pm 0.05 \mathrm{Aa}$ & $2.88 \pm 0.02 \mathrm{Ac}$ & & $0.91 \pm 0.05 \mathrm{Ba}$ & $0.96 \pm 0.01 \mathrm{Aa}$ \\
70 & $2.60 \pm 0.13 \mathrm{Ab}$ & $2.68 \pm 0.05 \mathrm{Aa}$ & & $0.97 \pm 0.01 \mathrm{Ab}$ & $0.96 \pm 0.02 \mathrm{Aab}$ \\
90 & $2.60 \pm 0.13 \mathrm{Ab}$ & $2.60 \pm 0.13 \mathrm{Ba}$ & $0.97 \pm 0.01 \mathrm{Ab}$ & $0.97 \pm 0.01 \mathrm{Aab}$ \\
\hline
\end{tabular}

of CARB (Fig. 3 and $30 \mathrm{~d}$ ), suggesting a possible adaptation of the microorganism in the biomixture to CARB. However, a significant inhibitory effect on microbial functional diversity was observed following the third application of CARB on $60 \mathrm{~d}$ (Fig. 3 and $60 \mathrm{~d}$ ). Interestingly, by $20 \mathrm{~d}$ after the third CARB application, the system had already recovered to the control level (Fig. 3, 70 and $90 \mathrm{~d}$ ). These results demonstrate that CARB does not have an irreversible effect on the microbial functional diversity after repeated applications, supporting previously reported results from repeated CARB pulses in soil $\left(4 \times, 10 \mathrm{mg} \mathrm{kg}^{-1}\right)$ by Yu et al. (2009). In our study, we also found a stimulatory effect on the microbial functional diversity, and such an effect has also been reported for other soil pesticides, such as glyfosate (Ratcliff et al., 2006).

The diversity indices Shannon's $(H)$ and Shannon's evenness $(U)$ were used to evaluate the richness and homogeneity, respectively, of the microorganism populations present in the biomixture. The results of the diversity index (Shannon's) of the CARB-contaminated biomixture indicate that the richness of the microorganisms was not significantly altered by repeated CARB applications of CARB (Table 2). Only $10 \mathrm{~d}$ after CARB application, the richness of the microorganisms was higher $(H=2.86)$ compared to the control $(H=2.30)$, indicating a possible stimulation of the microorganisms in the CARB biomixture. On the other hand, the addition of three successive applications of CARB at $40 \mathrm{mg} \mathrm{kg}^{-1}$ did not cause any changes in the level of microorganism homogeneity $(U)$ compared to that of the control (Table 2). These $U$ values (ranging from 0.93 to 0.97 ) indicate that the microbial communities in the CARB-contaminated biomixture were stable and that the balance between the different microorganisms was not altered. However, it is important to note that the results obtained by BiologEcoplate, only represents the response of fast-growing cultivable bacterial communities. Muñoz-Leoz et al. (2011) reported that addition of fungicide tebuconazole caused a increasing in AWCD, species richness $(S)$ and Shannon's diversity $(H)$ values after $90 \mathrm{~d}$ of pesticide application. These results were attributed to the killing of the fungi product from application of fungicide and therefore a decreasing in the competition for nutrients. In this sense the biomixture would offer one more appropriate environment for the development of both communities of bacteria and fungi, more than soil alone, because as shown below, both communities of bacteria and fungi were not significantly altered after three successive CARB applications in high doses.

\subsection{Cell enumeration}

The results of the CFU analysis for the cultivable bacteria, fungi and Actinomycetes after the three successive CARB applications are shown in Table 3. No significant differences in CFU numbers were found between the control and the experimental conditions $(p>0.05)$ after the first and second CARB applications. A reduction in the CFUs of cultivable bacteria was evident immediately after the third application of CARB ( 60 and $70 \mathrm{~d}$ ), but the CFU values increased to the same level as the controls during the subsequent $30 \mathrm{~d}$ of incubation (Table 3). Fungi CFU values were not significantly reduced $(p<0.05)$ after each CARB application compared to those of the control. This finding suggests that the fungi in the biomixture were robust and resistant to the presence of CARB. Actinomycetes were sensitive to the presence of the pesticide (Table 3). A significant decrease $(p<0.05)$ in the CFUs of the actinomycetes was observed $10 \mathrm{~d}$ after each CARB pulse $(10,40$ and $70 \mathrm{~d})$ compared with the control. However, the CFU values of cultivable actinomycetes were similar to those of the control at the end of the experiment. In general, the CFU recovery of cultivable bacteria, fungi and Actinomycetes in the CARB-contaminated biomixture were coincident with a decrease in the pesticide concentration (Fig. 1). Similar results were reported by Coppola et al. (2011), where culturable bacteria in a biomixture composed by $60 \%$ of pruning residues and $40 \%$ of straw not was significantly affected after successive applications of a mixture of fungicides. However, contrary to the results reported here, these authors found that culturable fungi were affected by the presence of pesticides. These differences could be attributed to the different physicochemical properties of the biomixtures or because in this work was added only one fungicide in repeated application and not as mixture of fungicides. On the other hand, has been reported that application of pesticide in soil caused inhibitory effects on bacterial, fungal communities during the initial periods after pesticide application (Chu et al., 2008) which were recovered in time. In this context, biomixture is showed as an alternative more robust, given that culturable bacterial and fungal communities were more stable in the time and only actinomycetes were more susceptible to the presence of CARB in the biomixture, which agrees with the results reported by Chu et al. (2008).

\subsection{DGGE profiles}

The structure of the bacterial, fungi and actinomycetes communities was evaluated by DGGE during the three successive CARB pulses (Fig. 4). The DGGE lanes from the contaminated biomixture

Table 3

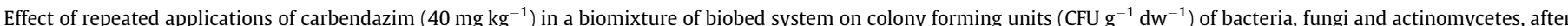
$90 \mathrm{~d}$ of incubation at $25 \pm 2{ }^{\circ} \mathrm{C}$.

\begin{tabular}{|c|c|c|c|c|c|c|c|c|}
\hline \multirow[b]{2}{*}{ M.O (CFU g $\left.{ }^{-1}\right)$} & \multirow[b]{2}{*}{ Treatment } & \multicolumn{7}{|l|}{ Time $(\mathrm{d})$} \\
\hline & & 0 & 10 & 30 & 40 & 60 & 70 & 90 \\
\hline \multirow[t]{2}{*}{ Bacteria $\times 10^{6}$} & Control & $15.5 \pm 1.7$ & $12.5 \pm 2.4$ & $27.5 \pm 1.1$ & $43.1 \pm 2.9$ & $38.1 \pm 2.4$ & $29.5 \pm 1.2$ & $31.4 \pm 2.5$ \\
\hline & CARB & $14.5 \pm 1.4$ & $12.1 \pm 1.6$ & $26.5 \pm 1.0$ & $40.6 \pm 3.2$ & $22.5 \pm 2.3$ & $18.5 \pm 1.4$ & $32.2 \pm 2.8$ \\
\hline \multirow[t]{2}{*}{ Fungi $\times 10^{5}$} & Control & $3.4 \pm 1.2$ & $3.5 \pm 1.2$ & $7.8 \pm 1.1$ & $7.5 \pm 1.7$ & $7.2 \pm 1.3$ & $6.5 \pm 1.7$ & $7.4 \pm 0.1$ \\
\hline & CARB & $3.2 \pm 1.7$ & $3.6 \pm 0.9$ & $7.2 \pm 1.2$ & $7.6 \pm 1.2$ & $7.5 \pm 1.1$ & $6.9 \pm 1.4$ & $7.8 \pm 0.2$ \\
\hline \multirow[t]{2}{*}{ Actinomycetes $\times 10^{5}$} & Control & $17.4 \pm 1.2$ & $33.0 \pm 3.2$ & $21.0 \pm 0.7$ & $28.5 \pm 1.0$ & $21.0 \pm 5.0$ & $24.5 \pm 1.0$ & $24.5 \pm 1.2$ \\
\hline & CARB & $16.5 \pm 2.4$ & $23.5 \pm 1.0$ & $21.5 \pm 1.0$ & $16.5 \pm 1.9$ & $24.5 \pm 2.0$ & $15.5 \pm 1.4$ & $21.5 \pm 0.9$ \\
\hline
\end{tabular}


(a)

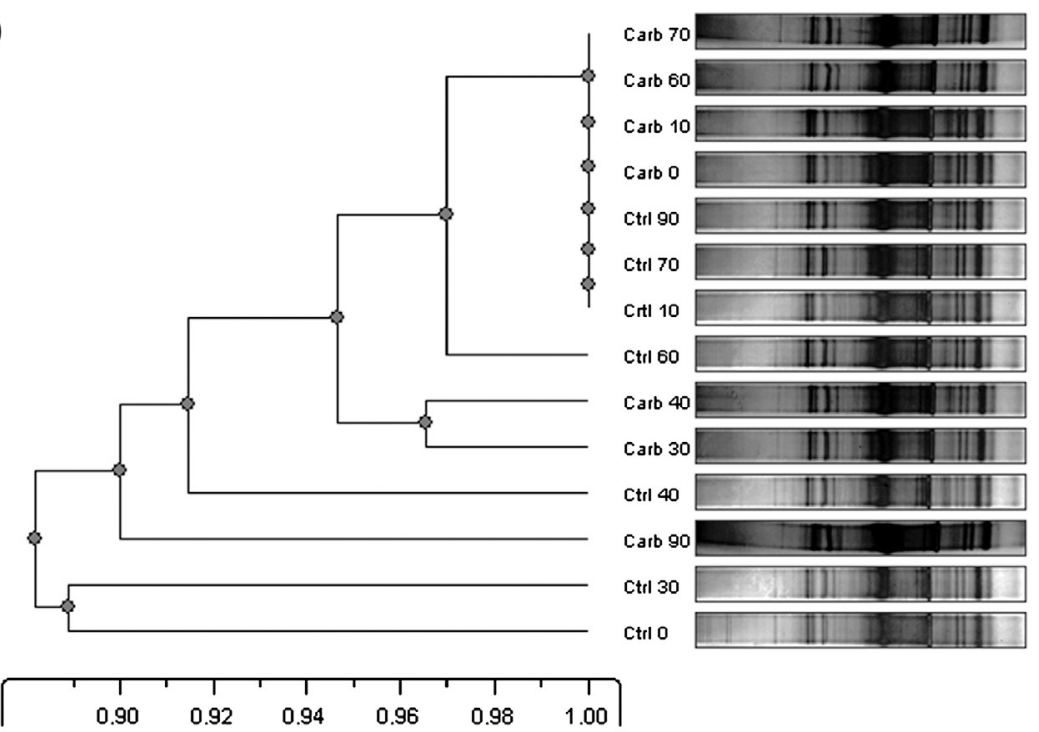

(b)
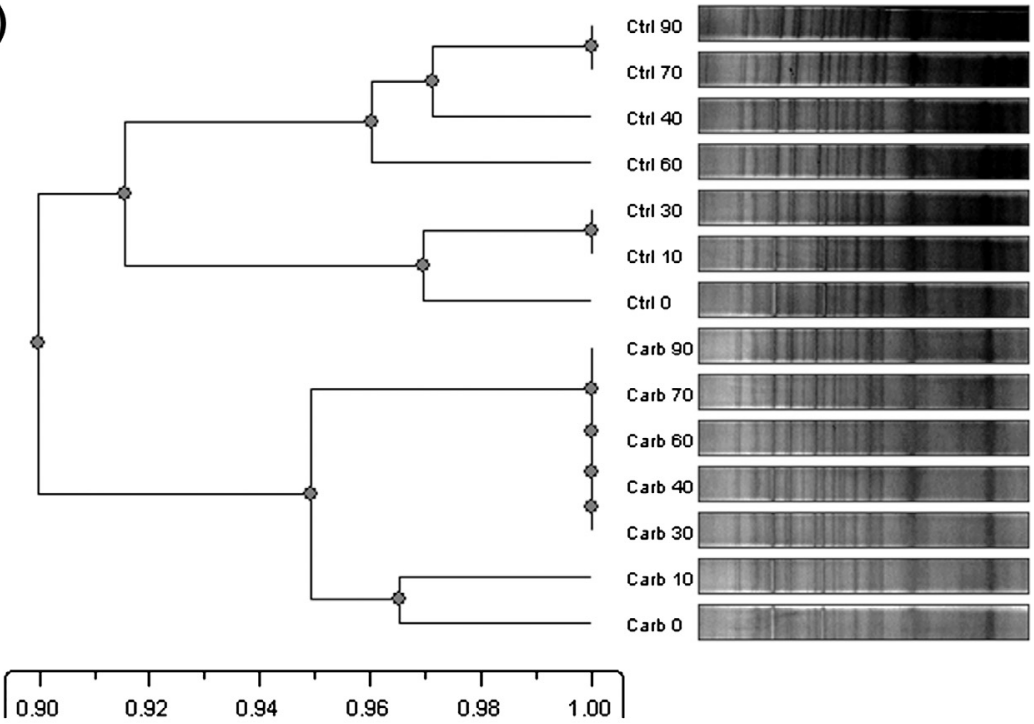

(c)

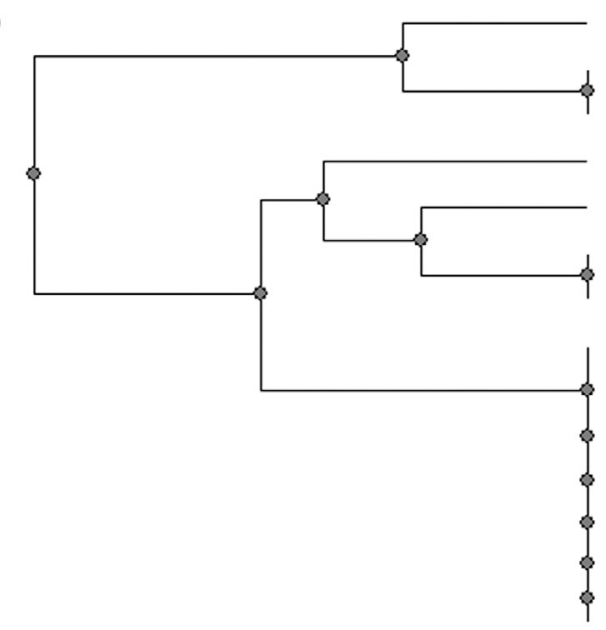

20

Cato

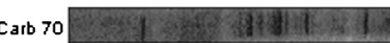

Carb 60

Carb 40

Ctıl 90

Ctrl 70

Ctıl 60

Carb 30

Carb 10

Carb

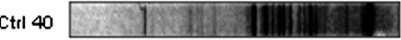

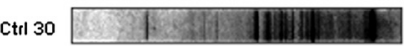

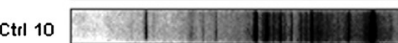

Ctrlo

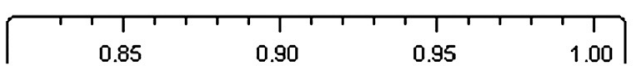

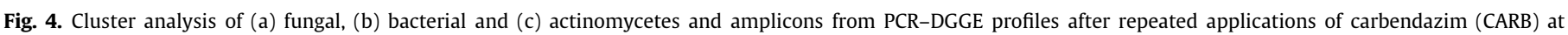
$40 \mathrm{mg} \mathrm{kg}^{-1}$. DNA was isolated at 0, 10, 30, 40,60, 70, and $90 \mathrm{~d}$ (Controls (Crtl) and carbendazim treatments (Carb)). 
and the control samples are denoted CARB 0 to CARB 90 and Ctrl 0 to $C \operatorname{trl} 90$, respectively, where the number indicates the sampling day.

The DGGE profiles of the fungal communities show an equally intense set of DGGE bands in all analysed samples, indicating the presence of a large number of equally abundant ribotypes in both the treatment and the control (Fig. 4a). Despite these similarities, UPGMA clustering revealed the existence of several groups. However, a high similarity ( $>90 \%$ ) was found between these groups, indicating that the fungicide CARB produced only minimal variations in the structure of the biomixture fungal community, which were restored by the end of the experiment.

The bacterial communities formed two major clusters (Fig. 4b): one group was composed of the control samples (Ctrl 0 to Ctrl 90), and the other group was composed of the corresponding contaminated samples (Carb 0 to Carb 90). This observation demonstrates that CARB caused variation in the bacterial communities of the biomixture, which is consistent with the findings for the CFUs of the cultivable bacteria and the microbial functional diversity. However, this variation in bacterial communities was low, which is revealed by the high (over 90\%) similarity in the DGGE patterns.

The comparisons between the DGGE patterns of the actinomycetes communities are shown in Fig. 4c. The DGGE patterns representing the actinomycetes communities in the biomixture samples had high similarity indices ( $>85 \%$ ). A few differences can be seen between the contaminated samples and the controls. However, these differences cannot be completely attributed to the presence of CARB in the biomixture. As shown in Fig. 4c, a large number of equally abundant ribotypes in both the contaminated samples and the controls were observed, indicating that the actinomycetes communities were robust and endured even with the repeated CARB applications.

The information provided by the DGGE patterns of the bacteria, fungi and actinomycetes demonstrates that microbial communities in the biomixture treated with CARB remained relatively stable over time or recovered their diversity after CARB degradation. This finding is consistent with the results of Coppola et al. (2011), who reported changes within the microbial DGGE profiles after the addition of fungicides. These differences were only temporary, and the microbial communities were restored to their original robustness by the end of the experimental period. In a recent study, Marinozzi et al. (in press) reported that the repeated application of the fungicides azoxystrobin, penconazole and fludioxonil caused significant changes in the structure of the microbial population in a biomixture of the biobed system that was composed of straw and pruning residue. Our results indicated that there was little change after repeated CARB applications. However, these differences in our results could be due to differences in the chemical composition of the pesticides used, differences in the application frequency, differences in the soil type and/or differences in the indigenous microbial composition.

On the other hand, in the biobed system, the fundamental ecological role of the microorganisms is to decompose the organic matter in order to generate chemical energy. The DGGE cluster analysis shown that bacteria some how are more susceptible to the chemical stress created by the addition of pesticide, because the mayor differences are between the treatments and the controls. In contrast, fungi and actinobacteria did not show this cluster separation between the treatments and controls, suggesting a more robust ecological role.

The results obtained from the DGGE analysis were in accordance with those obtained with the BiologEcoplate ${ }^{\mathrm{TM}}$. Indeed, both methods showed that the fingerprint of the microbial communities in the contaminated and control biomixtures did not vary significantly from one another. Moreover, the results from both the DGGE and the BiologEcoplate ${ }^{\mathrm{TM}}$ methods were in accordance with those obtained from the viable cell count, from which no significant differences $(p>0.05)$ could be observed after $90 \mathrm{~d}$ of incubation.

\section{Conclusion}

Herein, a well-studied biomixture of straw, peat and soil that is commonly used in on-farm biopurification systems demonstrated the capacity to dissipate CARB at a high rate. The measured enzymatic activities were only transiently susceptible to pesticide exposure, and enzyme activity levels were able to recover completely after CARB dissipation. The viable cell count, the carbon source utilisation profiles and the DGGE analysis all demonstrated that the microbial communities were stable after CARB addition. Overall, the results reported in this work not only reinforce the idea of the great dissipation capacity of the traditional biomixture but also demonstrate the robustness of this biological system from a microbiological viewpoint. This study highlights the potential for using a traditional biomixture for the biodepuration of contaminated agricultural residues, although the effects of the pesticide mixtures (including insecticides, herbicides and fungicides) on the biomixture must be further studied, as actual field applications increasingly make use of the combination of several pesticide types.

\section{Acknowledgements}

This work was supported by FONDECYT project No 11100236.

\section{References}

Beigel, C., Charnay, M.P., Barriuso, E., 1999. Degradation of formulated and unformulated triticonazole fungicide in soil: effect of application rate. Soil Biol. Biochem. 31, 525-534.

Casida Jr., L.E., 1977. Microbial metabolic activity in soil as measured by dehydrogenase determinations. Appl. Environ. Microbiol. 34, 630-636.

Castillo, Md.P., Torstensson, L., 2007. Effect of biobed composition, moisture, and temperature on the degradation of pesticides. J. Agric. Food Chem. 55, 5725 5733.

Castillo, Md.P., Stenstrom, J., Ander, P., 1994. Determination of manganese peroxidase activity with 3-methyl-2-benzothiazolinone hydrazone and 3(dimethylamino)benzoic acid. Anal. Biochem. 218, 399-404.

Castillo, Md.P., Torstensson, L., Stenstrom, J., 2008. Biobeds for environmental protection from pesticide use - a review. J. Agric. Food Chem. 56, 6206-6219.

Chowdhury, A., Pradhan, S., Saha, M., Sanyal, N., 2008. Impact of pesticides on soil microbiological parameters and possible bioremediation strategies. Indian J. Microbiol. 48, 114-127.

Chu, X.Q., Fang, H., Pan, X.D., Wang, X., Shan, M., Feng, B., Yu, Y.L., 2008. Degradation of chlorpyrifos alone and in combination with chlorothalonil and their effects on soil microbial populations. J. Environ. Sci. China 20, 464-469.

Coppola, L., Castillo, M.D., Monaci, E., Vischetti, C., 2007. Adaptation of the biobed composition for chlorpyrifos degradation to southern Europe conditions. J. Agric. Food Chem. 55, 396-401.

Coppola, L., Comitini, F., Casucci, C., Milanovic, V., Monaci, E., Marinozzi, M., Taccari, M., Ciani, M., Vischetti, C., 2011. Fungicides degradation in an organic biomixture: impact on microbial diversity. New Biotechnol. 29, 99-106.

Cycoń, M., Wójcik, M., Borymski, S., Piotrowska-Seget, Z., 2012. A broad-spectrum analysis of the effects of teflubenzuron exposure on the biochemical activities and microbial community structure of soil. J. Environ. Manage. 108, 27-35.

EFSA - European Food Safety Authority, 2010. Conclusion on the peer review of the pesticide risk assessment of the active substance carbendazim. EFSA J. 8 (5), 1508. http://dx.doi.org/10.2903/j.efsa.2010.1508.

Fang, H., Yu, Y.L., Chu, X.Q., Wang, X.G., Yang, X.E., Yu, J.Q., 2009. Degradation of chlorpyrifos in laboratory soil and its impact on soil microbial functional diversity. J. Environ. Sci. China 21, 380-386.

Fogg, P., Boxall, A.B.A., Walker, A., Jukes, A.A., 2003. Pesticide degradation in a 'biobed' composting substrate. Pest Manage. Sci. 59, 527-537.

Garland, J.L., Mills, A.L., 1991. Classification and characterization of heterotrophic microbial communities on the basis of patterns of community-level solecarbon-source utilization. Appl. Environ. Microbiol. 57, 2351-2359.

Grogan, H.M., Jukes, A.A., 2003. Persistence of the fungicides thiabendazole, carbendazim and prochloraz-Mn in mushroom casing soil. Pest Manage. Sci. $59,1225-1231$

Hane, B.G., Jager, K., Drexler, H.G., 1993. The Pearson product-moment correlation coefficient is better suited for identification of DNA fingerprint profiles than band matching algorithms. Electrophoresis 14, 967-972.

Heuer, H., Krsek, M., Baker, P., Smalla, K., Wellington, E.M.H., 1997. Analysis of actinomycete communities by specific amplification of genes encoding $16 \mathrm{~S}$ 
rRNA and gel-electrophoretic separation in denaturing gradients. Appl. Environ. Microbiol. 63, 3233-3241.

Imfeld, G., Vuilleumier, S., 2012. Measuring the effects of pesticides on bacterial communities in soil: a critical review. Eur. J. Soil Biol. 49, 22-30.

Kalia, A., Gosal, S.K., 2011. Effect of pesticide application on soil microorganisms Arch. Agron. Soil Sci. 57, 569-596.

Karanasios, E., Tsiropoulos, N.G., Karpouzas, D.G., Menkissoglu-Spiroudi, U., 2010. Novel biomixtures based on local Mediterranean lignocellulosic materials: evaluation for use in biobed systems. Chemosphere 80, 914-921.

Karanasios, E., Tsiropoulos, N.G., Karpouzas, D.G., 2012. On-farm biopurification systems for the depuration of pesticide wastewaters: recent biotechnological advances and future perspectives. Biodegradation 23, 787-802.

Marinozzi, M., Coppola, L., Monaci, E., Karpouzas, D.G., Papadopoulou, E. Menkissoglu-Spiroudi, U., Vischetti, C., in press. The dissipation of three fungicides in a biobed organic substrate and their impact on the structure and activity of the microbial community. Environ. Sci. Pollut. Res. Int. (in press) http://dx.doi.org/10.1007/s11356-012-1165-9.

Mazellier, P., Leroy, E., Legube, B., 2002. Photochemical behavior of the fungicide carbendazim in dilute aqueous solution. J. Photochem. Photobiol. A 153, 221 227.

Muñoz-Leoz, B., Ruiz-Romera, E., Antigüedad, I., Garbisu, C., 2011. Tebuconazole application decreases soil microbial biomass and activity. Soil Biol. Biochem. 43 2176-2183.

Muñoz-Leoz, B., Garbisu, C., Charcolsset, J.Y., Sanchez-Pérez, J.M., Antiguedad, I., Ruiz-Romera, E., 2013. Non-target effects of three formulated pesticides on microbially-mediated processes in a clay-loam soil. Sci. Total Environ. 449, 345-354.

Muyzer, G., Dewaal, E.C., Uitterlinden, A.G., 1993. Profiling of complex microbialpopulations by denaturing gradient gel-electrophoresis analysis of polymerase chain reaction-amplified genes-coding for 16s ribosomal-Rna. Appl. Environ. Microbiol. 59, 695-700.

Omirou, M., Dalias, P., Costa, C., Papastefanou, C., Dados, A., Ehaliotis, C., Karpouzas, D.G., 2012. Exploring the potential of biobeds for the depuration of pesticidecontaminated wastewaters from the citrus production chain: laboratory, column and field studies. Environ. Pollut. 166, 31-39.

Punitha, B.C., Hanumantharaju, T.H., Jayaprakash, R., Shilpashree, V.M., 2012 Acetamiprid impact on urease and phosphatase actvitiy in selected soils of southern karnataka. Int. J. Basic Appl. Chem. Sci. 2, 1-6.
Ratcliff, A.W., Busse, M.D., Shestak, C.J., 2006. Changes in microbial community structure following herbicide (glyphosate) additions to forest soils. Appl. Soil Ecol. 34, 114-124

Sanguinetti, C.J., Dias Neto, E., Simpson, A.J., 1994. Rapid silver staining and recovery of PCR products separated on polyacrylamide gels. Biotechniques 17, 914-921.

Schnürer, J., Rosswall, T., 1982. Fluorescein diacetate hydrolysis as a measure of total microbial activity in soil and litter. Appl. Environ. Microbiol 6, 256-1261.

Spliid, N.H., Helweg, A., Heinrichson, K., 2006. Leaching and degradation of 21 pesticides in a full-scale model biobed. Chemosphere 65, 2223-2232.

Srinivasulu, M., Rangaswamy, V., 2013. Effect of insecticides alone and in combination with fungicides on enzyme activities in soils. Int. J. Environ. Sci. Technol. 10, 341-350.

Srinivasulu, M., Jaffer Mohiddin, G., Subramanyam, K., Rangaswamy, V., 2012. Effect of insecticides alone and in combination with fungicides on nitrification and phosphatase activity in two groundnut (Arachis hypogeae L.) soils. Environ. Geochem. Health 34, 365-374.

Tabatabai, M.A., Bremner, J.M., 1969. Use of p-nitrophenyl phosphate for assay of soil phosphatase activity. Soil Biol. Biochem. 1, 301-307.

Torstensson, L. Castillo, M.d.P. 1997. Use of biobeds in Sweden to minimize environmental spillages from agricultural spraying equipment. Pestic. Outlook 8, 24-27.

Tortella, G.R., Rubilar, O., Castillo, M.d.P., Cea, M., Mella-Herrera, R., Diez, M.C., 2012. Chlorpyrifos degradation in a biomixture of biobed at different maturity stages. Chemosphere 88, 224-228.

Vischetti, C., Monaci, E., Cardinali, A., Casucci, C., Perucci, P., 2008. The effect of initial concentration, co-application and repeated applications on pesticide degradation in a biobed mixture. Chemosphere 72, 1739-1743.

White, T., Bruns, T., Lee, S., Taylor, J., 1990. Amplification and direct sequencing of fungal ribosomal RNA genes for phylogenetics. In: Innis, M., Gelfand, D. Shinsky, J., White, T. (Eds.), PCR Protocols: A Guide to Methods and Applications. Academic Press, pp. 315-322.

Yan, P., Lu, M., Guan, Y.M., Zhang, W.M., Zhang, Z.Z., 2011. Remediation of oil-based drill cuttings through a biosurfactant-based washing followed by a biodegradation treatment. Bioresource Technol. 102, 10252-10259.

Yu, Y., Chu, X., Pang, G., Xiang, Y., Fang, H., 2009. Effects of repeated applications of fungicide carbendazim on its persistence and microbial community in soil. J. Environ. Sci. 21, 179-185. 